\title{
Students' and Teacher's Insight on the Flipped Classroom Model in Academic Writing Class
}

\author{
Hamamah, Amanda Vira Maharani, Ressi Maulidina Delijar
}

\begin{abstract}
This study aims to investigate the insights of students and teacher in the implementation of online-based instruction with the Flipped Learning method applied in academic writing class, where students get material online from the teacher and study independently at home. Flipped classroom is basically a combination of e-learning and face-to-face instructional principles. This study involved Indonesian university students and 1 teacher who applied flipped learning method in an academic writing class. The result shows that students tend to like this method because it saves more time and the material can be repeated according to their needs. On the other hand, the teacher also likes the implementation of this method because students become more active in discussions with the knowledge they have gained prior to the class. However, students also admit that they are still unfamiliar with online learning platform used. The teacher also has difficulty in finding suitable teaching materials that can attract students' interests. However, in general, students and teacher both agree that the implementation of flipped learning in writing class is suitable.
\end{abstract} Class

Keywords: Flipped Classroom, Perception/Insights, Writing

\section{INTRODUCTION}

$\mathrm{W}_{\mathrm{e}}$ live in a digital era where we can be connected through the internet using many choices of devices, such as computer, laptop, and smartphone. This convenience of life can be utilized and applied in educational method as well. As the curriculum is growing year by year, device can take part as a tool to do an interactive activity, namely online tutorial and quiz [1]. ICT or Information and Communication Technology is not a new thing in developing countries nowadays. ICT here refers to the internet and communication devices. ICT is changing the society and lifestyle and also influencing all aspects of life in every human being, including education [2]. The United Nations Educational, Scientific and Cultural Organization [3] stated that ICT complete the education, because technology bridges the gap between what students' and teachers' needs. Therefore, ICT helps improve education.

ICT is in line with Indonesian Ministry of Education and Culture aims on National Education System [4] that the goal of national education is to develop students' potential in

Revised Manuscript Received on January 5, 2020.

* Correspondence Author

Hamamah", Linguistics Graduate Program, Universitas Brawijaya, Malang, Indonesia. Email: hamamah@ub.ac.id

Amanda Vira Maharani, Linguistics Graduate Program, Universitas Brawijaya, Malang, Indonesia. Email: amndvr@gmail.com

Ressi Maulidina Delijar, Linguistics Graduate Program, Universitas Brawijaya, Malang, Indonesia. Email: ressimdelijar@gmail.com many aspects, such as competent, creative, and independent. By familiarizing students with the ICT, it is hoped that the students can develop their competent, creative, and independent aspects. The implementation of ICT will also bring huge benefit for students, teacher, and the school. ICT is a supporting medium in learning process. It can nurture the students to be active learners as they conscious about what they need to find and learn, and then they can search it in unlimited time and space [5].

However, to implement ICT in education is still a challenge in a developing country like Indonesia. Suryani states that implementing ICT is not merely put the ICT in classroom, but beyond that. A study by Lubis [6] on the teachers' perception on ICT implementation in English Language Teaching (ELT) in Indonesia showed that the implementation of ICT faced many obstacles. The obstacles were inadequate knowledge and awareness in operating the ICT devices, the deficient internet access and facilities, and limited time in implementing the ICT-based classroom, moreover, there was short of ICT-based materials.

By looking at Indonesians' circumstances as stated in Lubis' findings, there are still a lot of challenges in Indonesia context to implement ICT in teaching and learning process. This limits educational institutions from conducting ICT based teaching and learning. One way to implement ICT in Indonesian educational context at this stage is by using it as efficient as possible. The teacher needs to utilize learning methods that includes ICT in the learning process but it should be friendly for the teacher, the students, and the school. It still needs to combine the face-to-face and the online instruction, so that there is a step-by-step process for the teacher in familiarizing themselves with the ICT based instruction. It should not only rely on the ICT devices and facilities at school, but it also provide the possibilities for students to learn outside class using the device that the students have.

Flipped classroom is a good method for the needs of ICT based instruction in Indonesian context because it is a combination of e-learning and face-to-face instructional principles by integrating activities, resources, support and assessment [7]. Reidsema, Kavanagh, \& Hadgraft [8] stated that flipped classroom is to engage the student by doing pre-class activity via online learning as a preliminary learning that is prepared by the instructor then aligned with in-class activity that is guide by the instructors. There are numerous studies about the effectiveness on flipped learning in many discipline studies; Mathematics [9], Biology [10], Medical [11], Business [12], Engineering [13], and in English itself [14]. The results of the study above said that flipped classroom was effective to improve students'

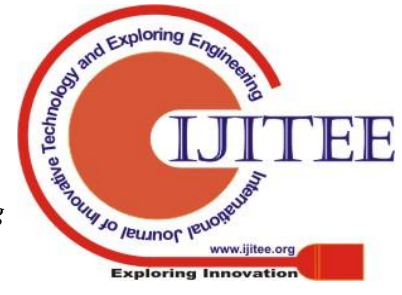




\section{Students' and Teacher's Insight on the Flipped Classroom Model in Academic Writing Class}

achievement on their study. Nevertheless, there is still few numbers talking about students and teacher perception on the implementation of flipped learning [15] [16], especially in Indonesian context.

Hence, this study wanted to look at how university students and teacher in Indonesian context perceive the instruction after the implementation of flipped learning.

\section{METHODS}

The data were collected from Indonesian university students and a teacher who experienced flipped learning method in an English Academic writing class. The flipped learning was tried out in the class. The students learned through a pre-class activity in an online platform, Edmodo, and in-class regular face-to-face activity. In Edmodo the teacher shared video, text, presentation, conducted the quiz and assignments and graded them. After the implementation of the flipped learning, questionnaires were given to the students to elicit their perceptions about the flipped learning. Out of 30 students in the class, 17 of them returned completed questionnaire on the flipped learning. Besides, the teacher also shared her perception on the flipped learning.

The questionnaire consisted of questions about the advantages, the disadvantages, and the suitability of the implementation of flipped classroom in the writing course. In each question, the participant could choose the available answers and or added their own answer if the choices available do not match what they think about this learning method. Students are also allowed to answer more than one choice. The questionnaire was spread out using Google Form.

\section{RESULTS AND DISCUSSION}

The findings in this study are presented based on two points of view, students' perceptions and teacher's perceptions of flipped classroom implementation. Perceptions, in this context, are advantages, disadvantages, and flipped classroom suitability in writing class.

\section{A. Students' Perceptions towards Flipped Classroom \\ - Advantages}

The data about the advantages of Flipped classroom implementation is taken from the questionnaire that has been distributed. The following are the data on the students' perception of the advantages of Flipped Classroom implementation.

Table- I: The Advantages of Flipped Classroom Model

\begin{tabular}{clcc}
\hline No. & \multicolumn{1}{c}{ Advantages } & $\begin{array}{c}\text { Percentag } \\
\text { e }\end{array}$ & N \\
\hline 1. & Able to understand better because the material is given as self-study/it can be repeated several times & $58.8 \%$ & 10 \\
2. & Learning the concept at home gives me more time to prepare questions on the thing I do not & $52.9 \%$ & 9 \\
& understand to be asked to the teacher in class. & $5.9 \%$ & 1 \\
\hline 3. & It does not take much time in class to explain about the material & Total Responses & 20 \\
\hline
\end{tabular}

Table- II: The Disadvantages of Flipped Classroom Model

\begin{tabular}{llll}
\hline No. & \multicolumn{1}{c}{ Disadvantages } & $\begin{array}{l}\text { Percentag } \\
\mathbf{e}\end{array}$ & $\mathbf{N}$ \\
\hline 1. & The access of the material is difficult (internet access) & $5.9 \%$ & 1 \\
2. & Unfamiliarity with Edmodo & $52.9 \%$ & 9 \\
3. & Difficulties in understanding the material because of the language & $41.2 \%$ & 7 \\
4. & It is easier to understand if the material is explained face to face. & $5.9 \%$ & 1 \\
\hline & & Total Responses & 18 \\
\hline
\end{tabular}

Being able to choose more than one choice, the total responses recorded were more than 17 . The data are sorted from the highest percentage to the lowest. $58.8 \%$ of students stated that the implementation of a flipped classroom helps them understand the material better. The learning material was shared by the teacher to the students through Edmodo. The availability of the material in an online platform makes it easy for the students to access it anytime. The students can access the materials themselves as many times as they need to get a better understanding. This is very different from traditional or conventional class in which the students get explanation only once in the classroom without being able to rewind it.

Another advantage of implementing flipped classroom is to give students more time to prepare questions to be discussed in class (52.9\%). Short meeting time in class often prevents students from asking questions and getting detailed explanations from the teacher. With the implementation of flipped classroom, students have more time to list questions on aspects that they do not understand when studying at home. Likewise, teachers also have longer time to explain something in detail without having to build learning concepts in detail.

The third advantage is that it does not take much time in class to explain about the material $(5.9 \%)$. The time in class can be used for more discussions to clarify understanding than to explain the material because the students have learned the material independently outside class. 


\section{- Disadvantages}

In addition to the advantages of applying flipped learning method, students are also asked to answer questions about the disadvantages of implementing the flipped classroom method. The following are the results of the questionnaire on the disadvantages.

As explained before, the students can choose more than one answer.

The data in Table II show that the highest disadvantage is students' unfamiliarity with the learning platform used $(52.9 \%)$ that is Edmodo. The use of learning platforms needed familiarization of students to be able to use the platform. The unfamiliarity of students in using Edmodo become a challenge for them. The students are not yet accustomed to use this learning platform.

The second disadvantage with the percentage of $41.2 \%$ was about the difficulty in understanding the language used in the material. The language in the shared material is more difficult to understand compared to the teacher's explanation in class. $5.9 \%$ of the respondents stated that it was easier to understand teachers' explanation in class. Teachers who explain in class directly use language that is easier for students to understand, language is also adapted to students' abilities, rather than online material such as videos.

However, surprisingly, students reported that difficulty accessing material because of the internet is not the main problem $(5.9 \%)$. It shows that students in Indonesia already have good access to the internet.

\section{- Suitability}

This section asked students' opinion whether the students think the implementation of the flipped classroom method is relevant and suitable for the writing class. The question was open ended, not multiple choices. Therefore, the participants must explain in their answer using their own sentences. After seeing the responses of the participants, it can be concluded that 15 participants said that the implementation of this method is suitable for the writing class $(88.2 \%)$. One of them did not state the reason, while one participant said that it might be suitable and might be not suitable (5.9\%). The students' stated that the flipped learning was suitable for writing class for several reasons. The following are the reasons of students saying that flipped classroom is suitable for writing class.

\section{"It helps a lot in understanding the material"}

Students respond that using this method can help them understand the material. This is because the material distributed via the learning platform, Edmodo, can be studied at home. The students' time for understanding the material is longer than their time inside the classroom.

\section{"It helps us to study and learn whenever and wherever"}

Related to the previous point that, flipped classroom is considered to be able to help students in understanding the material, the application of this method can also encourage students to learn wherever and whenever. Thus, students are not limited by space and time in learning.

\section{"It is more efficient and less time-wasting"}

Besides students can learn anywhere at any time, the students consider the implementation of this method in writing class can make the class more efficient because the teacher does not need to explain the material too detail, but more in practice and consultation. Practice and consultation are needed in writing class, rather than explaining learning material in detail.

"Writing is a difficult skill to do at the moment, so I think this flipped classroom really help me to prepare my writing, brainstorming my idea, and etc."

"Students have enough time to prepare assignments and material given"

Students also report that the implementation of this method is very suitable for writing class, because writing takes longer time to prepare and determining the topic. The flipped classroom provide more time for the students to prepare their writing outside the class. If their preparation is not limited by short class time, students will certainly find it easier to think and brainstorm about the chosen topic and look for the resources to support their writing. In that way, writing course will be more effective and productive.

"Writing essay needs a lot of material from other sources. Flipped classroom is really helpful for me to prepare in advance by finding sources before I start to write."

It is undeniable that writing is not easy. Writing takes time to read many sources so that the writing produced becomes meaningful and useful. With flipped learning method, students can explore various sources before writing an essay, because the time allotted is not limited in class time.

Additionally, the students also report that the use of flipped learning by utilizing online-based learning platforms really helps them to save paper, because student assignments are collected online.

"It does not use a lot of paper, so we do not need to print and re-print our writing many times. This learning method helps in saving the earth by reducing the use of paper."

As can be seen from the various aforementioned reasons, most students agree with the implementation of flipped classroom in the writing class. However, there was also one student who feel the implementation of flipped learning method in writing course was not fully suitable.

"Well, for me, it is 50:50, I guess because there are some things that should be easier to be understood if explained directly by the teacher."

The student had difficulties in learning the provided video and other learning material.

\section{B. Teacher's Perceptions towards Flipped Classroom}

In addition to presenting the student's perspective, this study also presents perceptions about the implementation of the flipped classroom learning method from the teacher's perspective. This is done to obtain more extensive information from different course stakeholders. The teacher's perceptions are also presented in three parts, advantages, disadvantages, and suitability of the flliped

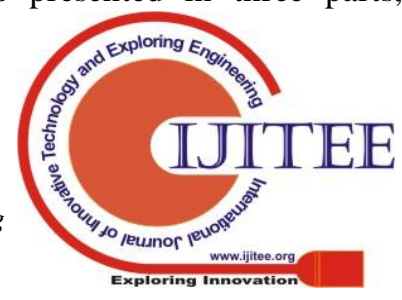




\section{Students' and Teacher's Insight on the Flipped Classroom Model in Academic Writing Class}

learning method for academic writing course.

\section{- Advantages}

The response was provided by the teacher who taught writing class using the flipped classroom method. According to the teacher, this method not only facilitates the teacher, but also makes it easier for students. Just as students' perceptions, the teacher also feels that this method is helpful because

students are more involved in classroom after having lesson at home in advanced. In addition, the teacher also considers that students can understand better when the material is given before class.

"It is convenient for me as the teacher and also for the students. I think if they can learn the material first, they can take time to comprehend the material and do the task at home in a more comfortable situation. Some students only need to repeat the material presented once or twice, while other students may need three or four times to understand the material presented. They can adjust their learning according to their pace."

The teacher also states that learning before class is very helpful, because it can make students more active in classroom discussion. Active discussion happens because the students already have the prior knowledge.

"Then, we can briefly discuss the main point and ask what they don't understand. It is saving the class time, so we can discuss more in the class."

Thus, this learning method in addition to facilitating the teacher in building student activity in the classroom also saves time because the explanation of the topic has been done in advanced.

\section{- Disadvantages}

Different from the difficulty faced by students which was the unfamiliarity in using certain learning platforms, the teacher's difficulty was in terms of finding appropriate teaching materials for their students. This can be seen from the following statement.

"Finding the right video for students is rather hard, because we need to match what we are going to explain and is it already explained in the video or not. On the other hand, to make a self-video of ourselves explaining the material is rather hard to do too, because we need to film ourselves, then edit the video, and then upload to the web, meanwhile there is not so much time left before the implementation. If we don't include the video, I'm afraid the students will be bored or hardly understand the material. There's already an e-material that I compiled, so it is convenient for them to read, yet I have to provide other learning styles (visual learner, auditory learner, and kinesthetic learner)."

The teacher needs to be careful in finding suitable materials to be implemented in this learning method. This is because the selection of unattractive teaching materials can reduce student learning interest at home independently. Meanwhile, to make teaching material that is appropriate and interesting, it requires time and funding. Thus, teacher needs extra energy before class to prepare student teaching materials.

\section{- Suitability}

The teacher considers that this method is relevant and suitable for writing class. This flipped learning method provided a longer consultation time with students.

"Yes, it is suitable for writing class. The reason is writing class needs a lot of consultation. Actually, consultation and feedback can be done online, yet it is easier if we can talk person by person. Moreover, I know my students better, by knowing what they want to write and their difficulties, and I can use the class time talk to them about that."

Through this method, the teacher can assist students in writing more personally. Longer class time, allows teacher to provide one to one consultation time for students.

"Also I utilized the Edmodo as a medium to share what I suggest to their essay. By using learning platform, I can share what I want to share to improve their writing, such as e-material, writing tips, and additional information regarding the task."

In addition, teachers also realize the use of learning platforms such as Edmodo strongly supports the distribution of additional teaching materials related to the assignments given.

From the statement above, it can be seen that, in addition to the majority of students, teachers also tend to agree on the implementation of the flipped classroom learning method in writing class.

\section{CONCLUSION}

The implementation of flipped learning in academic writing class in Indonesian context is beneficial for both teacher and the students even though there are some challenges.

The flipped learning in academic writing class provided more time for the students to learn the topic. The students can repeatedly learn the material given online. Additionally, the students can prepare better before the class because they have more time to brainstorm their ideas and prepare sources for their writing topic. They can also prepare questions to be asked to the teacher in class about aspects of the lessons that they cannot understand during the independent online learning.

To the teacher, flipped classroom can lessen their difficulties in making students understand the teaching materials. The online materials that were provided to the students prior to the meeting have provided most of the explanation that needs to be delivered to the students. The students already have knowledge before coming to the class, so that the teacher can lead discussion on the learning topic with a more active participation from the students. The flipped learning makes the instruction more student-centered.

The challenge faced by the students in flipped learning was in the form of unfamiliarity in using the online learning platform and the difficulties in understanding the English used by native speaker in the video. Likewise, teacher also
Blue Eyes Intelligence Engineering

\& Sciences Publication 
finds difficulty in finding suitable teaching materials that can adequately represent the topic to be discussed. However, both parties feel that flipped learning is suitable and relevant to the writing class. Online-based learning is considered to help a lot in writing class.

\section{REFERENCES}

1. Arnold-Garza, S. (2014). The Flipped Classroom Teaching Model and its Use for Information Literacy Instruction. Communications in Information Literacy, 8(1), pp. 7-22. Available http://dx.doi.org/10.15760/comminfolit.2014.8.1.161

2. Ratheeswari, K. (2018). Information Communication Technology in Education. Journal of Applied and Advanced Research, 3(1), pp. S45-S47. Available: https://dx.doi.org/10.21839/jaar.2018.v3S1.169

3. The United Nations Educational, Scientific and Cultural Organization. (2019). ICT in Education [Online]. Available: https://en.unesco.org/themes/ict-education

4. Ministry of Education and Culture Republic of Indonesia. (2013). Undang-Undang Nomor 20 tahun 2003 tentang Sistem Pendidikan Nasional, Pasal 3

5. Suryani, A. (2010). ICT in Education: Its Benefits, Difficulties, and Organizational Development Issues. Jurnal Sosial Humaniora, 3(1), pp. 106-123.

6. Lubis, A. H. (2018). ICT Integration in 21st Century Indonesian English Language Teaching: Myths and Realities. Cakrawala Pendidikan, 2018(1), pp. 11-21.

7. Gagnon, P., Mendoza, R., \& Carlstedt-Duke, J., A Technology-Enabled Flipped Classroom Model. In C. Reidsema, L. Kavanagh, R. Hadgraft $\&$ N. Smith (Eds.), The Flipped Classroom: Practice and Practices in Higher Education. Singapore: Springer Nature, 2017, pp. 211-228.

8. Reidsema, C., Hadgraft, R., \& Kavanagh, L., Introduction to the Flipped Classroom. In C. Reidsema, L. Kavanagh, R. Hadgraft \& N. Smith (Eds.), The Flipped Classroom: Practice and Practices in Higher Education. Singapore: Springer Nature, 2017, pp. 3-14.

9. Zakaria, E. \& Syamaun, M. (2017). The Effect of Realistic Mathematics Education Approach on Students' Achievement and Attitudes towards Mathematics. Mathematics Education Trends and Research, 1 (1), pp. $32-40$

10. Malto, G., Dalida, C., \& Lagunzad, C. (2018), Flipped Classroom Approach in Teaching Biology: Assessing Students' Academic Achievement and Attitude Towards Biology in 4th International Research Conference on Higher Education, KnE Social Sciences, pp. 540-554. DOI 10.18502/kss.v3i6.2403

11. Sezer, B., \& Abay, E. (2017). Looking at the Impact of the Flipped Classroom Model in Medical Education. Scandinavian Journal of Educational Research, 63 (6), pp. 853-868.

12. Kwon, J., \& Woo, H. (2017). The Impact of Flipped Learning on Cooperative and Competitive Mindsets. Sustainability, 10 (79), pp. 1-15. doi: 10.3390/su10010079.

13. Jdaitawi, M. (2019). The Effect of Flipped Classroom Strategy on Students Learning Outcomes. International Journal of Instruction, 12(3), pp. 665-680. https://doi.org/10.29333/iji.2019.12340a

14. Ahmed, M. A. E. A. S. (2016). The Effect of a Flipping Classroom on Writing Skill in English as a Foreign Language and Students' Attitude towards Flipping. US-China Foreign Language, 14(2), pp. 98-114. doi: http://dx.doi.org/10.17265/1539-8080/2016.02.003

15. Afrilyasanti R., Cahyono B. Y., \& Astuti U. P. (2017). Indonesian EFL Students' Perceptions on the Implementation of Flipped Classroom Model. Journal of Language Teaching and Research, 8(3), pp. 476-484.

16. Shih, W. L, \& Tsai, C. Y. (2017). Students' perception of a flipped classroom approach to facilitating online project-based learning in marketing research courses. Australasian Journal of Educational Technology, 33(5), pp. 32-49. https://doi.org/10.14742/ajet.2884

\section{AUTHORS PROFILE}

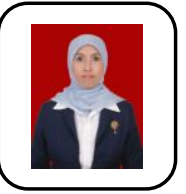

Hamamah, is an academic at the Faculty of Cultural Studies, Universitas Brawijaya. Hamamah's research interests are in the areas of: Writing for Research and Publication Purposes; Academic Writing; learning methods; Teaching English as a Foreign Language (TEFL and TESOL).

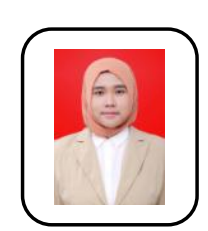

Amanda Vira Maharani, is a fresh graduate from Linguistics Graduate Program, Faculty of Cultural Studies, Universitas Brawijaya.

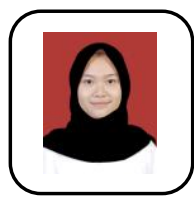

Ressi Maulidina Delijar, is a fresh graduate from Linguistics Graduate Program, Faculty of Cultural Studies, Universitas Brawijaya. 